\title{
Evaluation of the global longitudinal strain and segmental strain of the right ventricle with two-dimensional speckle-tracking echocardiography with elevation of the legs
}

\section{Evaluación de la deformación longitudinal global y segmentaria del ventrículo derecho con ecocardiografía bidimensional speckle-tracking con la elevación de las piernas}

\section{Zaira Y. García-López ${ }^{1 *}$ and Jesús Vargas-Barrón²}

${ }^{1}$ Department of Hospitalization, High Specialty Medical Unit, Cardiology Hospital, Centro Médico Nacional Siglo XXI, IMSS; ${ }^{2}$ Department of Echocardiography, Instituto Nacional de Cardiología Dr. Ignacio Chávez. Mexico City, Mexico

\begin{abstract}
Introduction: Speckle-tracking echocardiography has shown its usefulness in the evaluation of the right ventricle (RV) in healthy subjects and in pulmonary hypertension. It is unknown whether this technique could be sensitive to assess healthy RV with increases in preload. Methods: Consecutive subjects were studied without evidence of cardiopulmonary disease. They underwent speckle-tracking echocardiography in General Electric Vivid $7^{\circledR}$ equipment. The "segmental longitudinal strain" (SLS) and "global longitudinal strain" (GLS) of the RV was determined at rest and with an increase in the preload through elevation the legs to $45^{\circ}$. Results: We analyzed 31 subjects, 16 men and 15 women, aged 16-53 years, in which were measured SLS and GLS. Basal of the RV free wall: $-29.1 \pm 3.3$ versus $-32.7 \pm 5.5 \%, p=0.0002$. Mid of the RV free wall: $-28.6 \pm 6.4$ versus $-31.5 \pm 4.9 \%, p=0.001$. Apical of the free wall of the RV: $-21.9 \pm 6.5$ versus $-23.3 \pm 6.1 \%, p=0.118$. Basal inferoseptum: $-19.40 \pm 3.2$ versus $-18.9 \pm 3.0 \%, p=0.204$. Mid inferoseptum: $-19.3 \pm 3.2$ versus $-19 \pm 3.1 \%$, $p=0.249$. Apical septum: $-17.1 \pm 5.1$ versus $-17 \pm 5.4 \%, p=0.457$. GLS of the RV: $-23.06 \pm 3.4$ versus $-24.5 \pm 2.9 \%$, $p=0.002$. ICC: $0.773,95 \%$ Cl: $0.534-0.890, p<0.001$. Conclusions: This method was sensitive to detect differences in the GLS and SLS basal and mid of the RV free wall.
\end{abstract}

Key words: Speckle-tracking echocardiography. Segmental longitudinal strain. Right ventricle. Preload. Global longitudinal strain. Elevation of the legs. Mexico.

\section{Resumen}

Introducción: La ecocardiografía speckle-tracking (EST) ha mostrado su utilidad en la evaluación del ventrículo derecho (VD) en sujetos sanos y en hipertensión pulmonar. Se desconoce si esta técnica es sensible para evaluar el VD en sujetos sanos con aumento en la precarga. Método: Se evaluaron sujetos consecutivos sin evidencia de enfermedad cardiopulmonar. Se

\section{Correspondence:}

*Zaira Yadira García-López

Av. Cuauhtemoc, 330

Col. Doctores, Del. Cuauhtemoc

Date of reception: 13-04-2018

Date of acceptance: 10-10-2018

DOI: 10.24875/ACME.M19000003
Available online: 09-08-2019 Arch Cardiol Mex (Eng). 2019;89(1):15-19 www.archivoscardiologia.com 
realizó EST con equipo General Electric Vivid $7^{\circledR}$. La deformación longitudinal segmentaria (DLS) y la deformación longitudinal global (DLG) del VD se determinaron en reposo y con incremento en la precarga mediante la elevación de las piernas a $45^{\circ}$. Resultados: Analizamos 31 sujetos, 16 hombres y 15 mujeres. Edad: 16-53 años. Basal de la pared libre del VD: $-29.1 \pm$ 3.3 vs. $-32.7 \pm 5.5 \%, p=0.0002$. Medio de la pared libre del VD: $-28.6 \pm 6.4$ vs. $-31.5 \pm 4.9 \%, p=0.001$. Apical de la pared libre del VD: $-21.9 \pm 6.5$ vs. $-23.3 \pm 6.1, p=0.118$. Basal septum inferior: $-19.40 \pm 3.2$ vs. $-18.9 \pm 3.0 \%, p=0.204$. Medio septum inferior: $-19.3 \pm 3.2$ vs. $-19 \pm 3.1 \%, p=0.249$. Apical septal $-17.1 \% \pm 5.1$ vs. $-17 \pm 5.4, p=0.457$. DLG del VD: $-23.06 \pm 3.4$ vs. $-24.5 \pm 2.9 \%, p=0.002$. CCl: 0.773, IC 95\%: 0.534-0.890, $p<0.001$. Conclusiones: El método fue sensible para detectar diferencias en la DLG y DLS basal y media de la pared libre del VD.

Palabras clave: Ecocardiografía speckle-tracking. Deformación longitudinal segmentaria. Ventrículo derecho. Precarga. Deformación longitudinal global. Elevación de las piernas. México.

\section{Introduction}

Echocardiogram is a non-invasive procedure to estimate the morphology and function of the heart; two-dimensional (2D) speckle-tracking echocardiography (STE) is an echocardiographic technique that is used as a tool to measure longitudinal, circumferential, radial and global deformation of both ventricles ${ }^{1-3}$. STE uses natural acoustic markers that are speckles in a gray-scale seen in 2D-mode images, as a consequence of the sound pulse random backscattering in a tissue plane explored by echography in structures smaller than the ultrasound wavelength ${ }^{4}$. With this technology, random noise is accurately filtered and these speckles are monitored and analyzed frame by frame. Its advantages with regard to other echocardiographic techniques include high spatial and temporal resolution, its independence from the sound beam angle of incidence (which allows analyzing segments that are not in parallel alignment with the ultrasonic beam), its availability, affordability, portability and safety. These principles are similar to those used in magnetic resonance imaging ${ }^{5}$.

STE allows rapid and accurate assessment of the myocardial function, where strain $\varepsilon$ describes myocardial deformation, i.e., the fractional change in the length of a myocardial segment. It has no unit and it is generally expressed as a percentage (\%), and it can have positive or negative values that reflect lengthening or shortening, respectively. The term "global strain", or more precisely, "global longitudinal strain" or "global circumferential strain" generally refers to the average longitudinal or circumferential deformation components throughout the myocardium, which can be approached by the components of average segmental deformation in individual segments of the myocardial wall. Deformation values can be expressed for each segment (segmental strain, SLS) or as an average value for all segments (global strain, GLS) ${ }^{4}$.
In hemodynamic assessment with 2D echocardiography it is not usual for preload to be assessed; however, several animal studies have shown that assessment of the mechanics of left ventricle (LV) deformation with STE is sensitive to changes in loading conditions, and this should be emphasized, since the mechanics of LV deformation cannot be considered independent of the load, contractility indicators or lusitropism ${ }^{6}$.

STE has demonstrated its usefulness in the assessment of the RV in healthy subjects ${ }^{7}$ and in pulmonary hypertension ${ }^{8}$. Whether this technique is sensitive enough to assess changes in RV parameters without cardiopulmonary compromise with maneuvers that increase preload, such as raising the legs to $45^{\circ}$, is unknown. Leg elevation is a technique that has been used to increase preload in healthy subjects $^{9-11}$, post-heart transplant ${ }^{12}$, and in states of shock and hypotension ${ }^{13}$.

Preload is one of the main determinants of cardiac output. Classically, it has been defined as the maximum degree of stretching or tension of the myocardial fiber prior to starting ventricular contraction, and is determined by end-of-diastole sarcomere mean length. Clinically, this definition is not practical and is difficult to apply; as a result, it is replaced by more accessible ventricular filling measurements, such as intracavitary pressures or end-diastolic volumes. Although none of these parameters reflects the elongation of cardiac muscle fiber, they offer an accepted approximation of preload real value ${ }^{14}$.

Changes in preload or afterload conditions have been shown to affect the mechanics of LV deformation ${ }^{15}$.

For this reason our objective was to describe with STE what the behavior of RV GLS and SLS would be in a four-chamber approach with a change of position of the legs as an estimate that would suggest preload changes in subjects without prior cardiopulmonary pathology. 
Table 1. Percentage differences in segmental longitudinal strain and global longitudinal strain at rest and with leg elevation to $45^{\circ}$

\begin{tabular}{|l|c|c|c|}
\hline Assessed segment & $\begin{array}{c}\text { Baseline SLS and GLS \% } \\
\mathbf{n = 3 1}\end{array}$ & $\begin{array}{c}\text { SLS and GLS \% with leg elevation to } \\
\mathbf{n = 3 1}\end{array}$ & \begin{tabular}{c}
$\mathbf{p}$ \\
\hline Basal RV free wall
\end{tabular} \\
\hline Middle RV free wall & $-29.1 \pm 3.3$ & $-32.7 \pm 5.5$ & 0.0002 \\
\hline Apical RV free wall & $-28.6 \pm 6.4$ & $-31.5 \pm 4.9$ & 0.001 \\
\hline Basal lower septum & $-21.9 \pm 6.5$ & $-23.3 \pm 6.1$ & 0.118 \\
\hline Middle lower septum & $-19.4 \pm 3.2$ & $-18.9 \pm 3.0$ & 0.204 \\
\hline Apical septal & $-19.3 \pm 3.2$ & $-19 \pm 3.1$ & 0.249 \\
\hline GLS & $-17.1 \pm 5.1$ & $-17 \pm 5.4$ & 0.457 \\
\hline
\end{tabular}

GLS: global longitudinal strain; RV: right ventricle; SLS: segmental longitudinal strain.

\section{Method}

Using a case series design, consecutive subjects with no evidence of cardiopulmonary disease were assessed.

\section{Inclusion criteria}

Healthy subjects of both genders, with ages ranging between 16 and 53 years. Exclusion criteria: poor acoustic window, heart and lung disease diagnosis, not authorizing the performance of the echocardiogram.

Pulsed and continuous color Doppler 2D-mode transthoracic echocardiogram was performed. Subsequently, four, three and two-chamber 2D gray-scale images were acquired with a General Electric Vivid $7^{\circledR}$ equipment with a $3 \mathrm{MHz}$ transducer. The STE images were post-processed using the EchoPac program.

\section{Maneuver}

With the subjects at rest in the supine position and then with elevation of both legs to $45^{\circ}$ for 5 minutes, 2D-mode images were acquired with a four-chamber approach before and after the maneuver, with basal RV free wall, middle RV free wall, apical RV free wall, basal lower septum, mid-lower septal and apical septal GLS and SLS being determined with STE. The variables that were obtained were: GLS and SLS before and after leg elevation.

\section{Statistical analysis}

Continuous variables are expressed as the mean \pm standard deviation. The differences before and after the maneuver (leg elevation to $45^{\circ}$ ) were analyzed with Student's t-test for dependent samples. A p-value $<0.05$ was considered statistically significant. GLS and SLS intra-observer variability was estimated with the intra-class correlation coefficient and its respective 95\% confidence interval. The statistical analysis was carried out with the Excel $^{\circledR}$ and SPSS ${ }^{\circledR}$ version 16 statistical programs.

\section{Results}

Thirty-one subjects were analyzed, 16 men and 15 women with ages ranging from 16 to 53 years. GLS and SLS behavior before and after leg elevation to $45^{\circ}$ is shown in table 1 and figure 1; a box and whisker plot shows mean differences and the distribution is observed to be larger (i.e., higher dispersion), and there is also a positive bias for the subjects at rest (Fig. 2). The intra-class correlation coefficient was calculated: 0.773 , with a $95 \%$ confidence interval $(\mathrm{Cl})$ of 0.534 $0.890 ; p<0.001$.

\section{Discussion}

2D STE measures RV GLS and SLS with a four-chamber approach. We measured it in healthy subjects at rest and with position changes (leg elevation to $45^{\circ}$ ), a maneuver that was used with the purpose to increase preload. There are no previous studies on RV performing this maneuver. There are studies on LV where STE-observed longitudinal and circumferential strain has been calculated to be affected by acute changes in saline infusion-induced preload ${ }^{16}$. We obtained significant GLS and SLS differences in the basal and mid-RV free-wall 


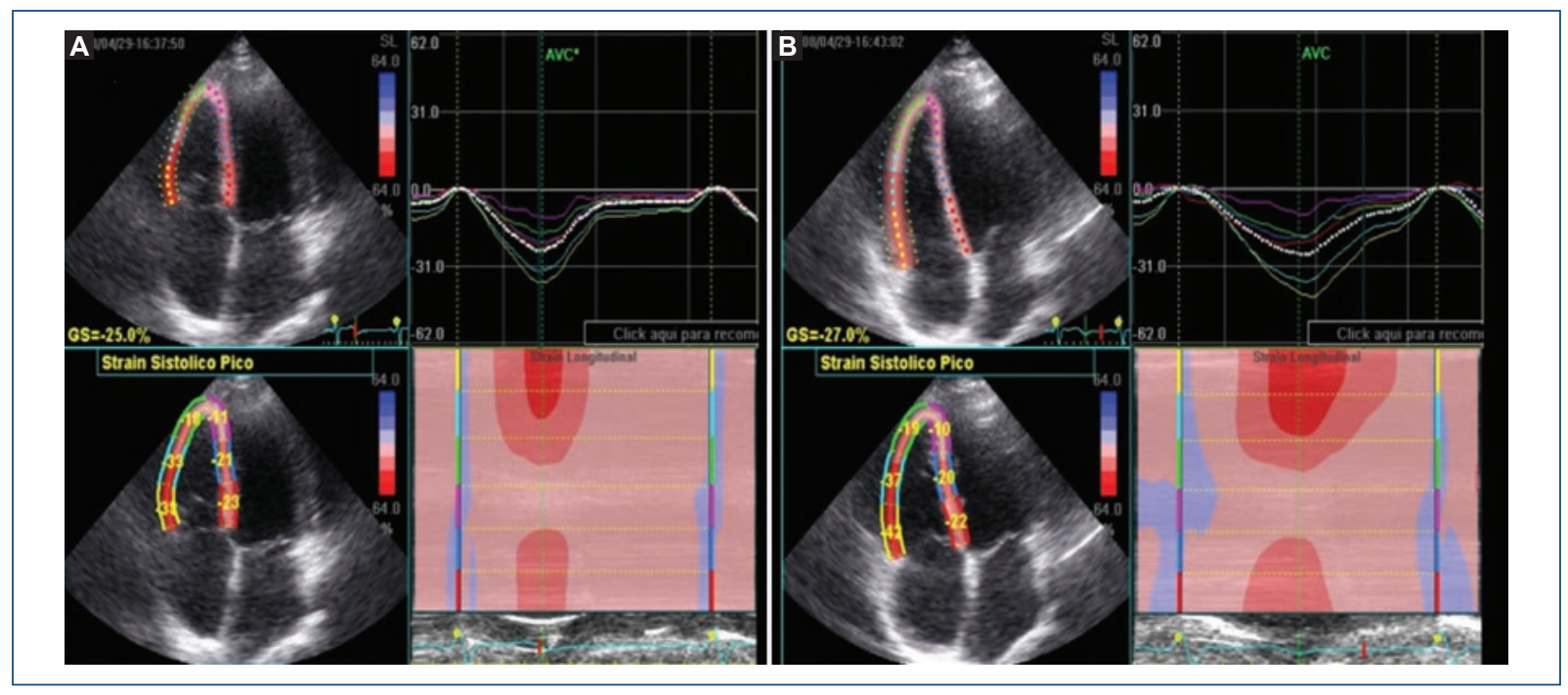

Figure 1. Right ventricle global and segmental longitudinal strain with speckle-tracking echocardiography four-chamber approach. We also observe the strain in the graph and in M-mode. A: rest. B: leg elevation to $45^{\circ}$.

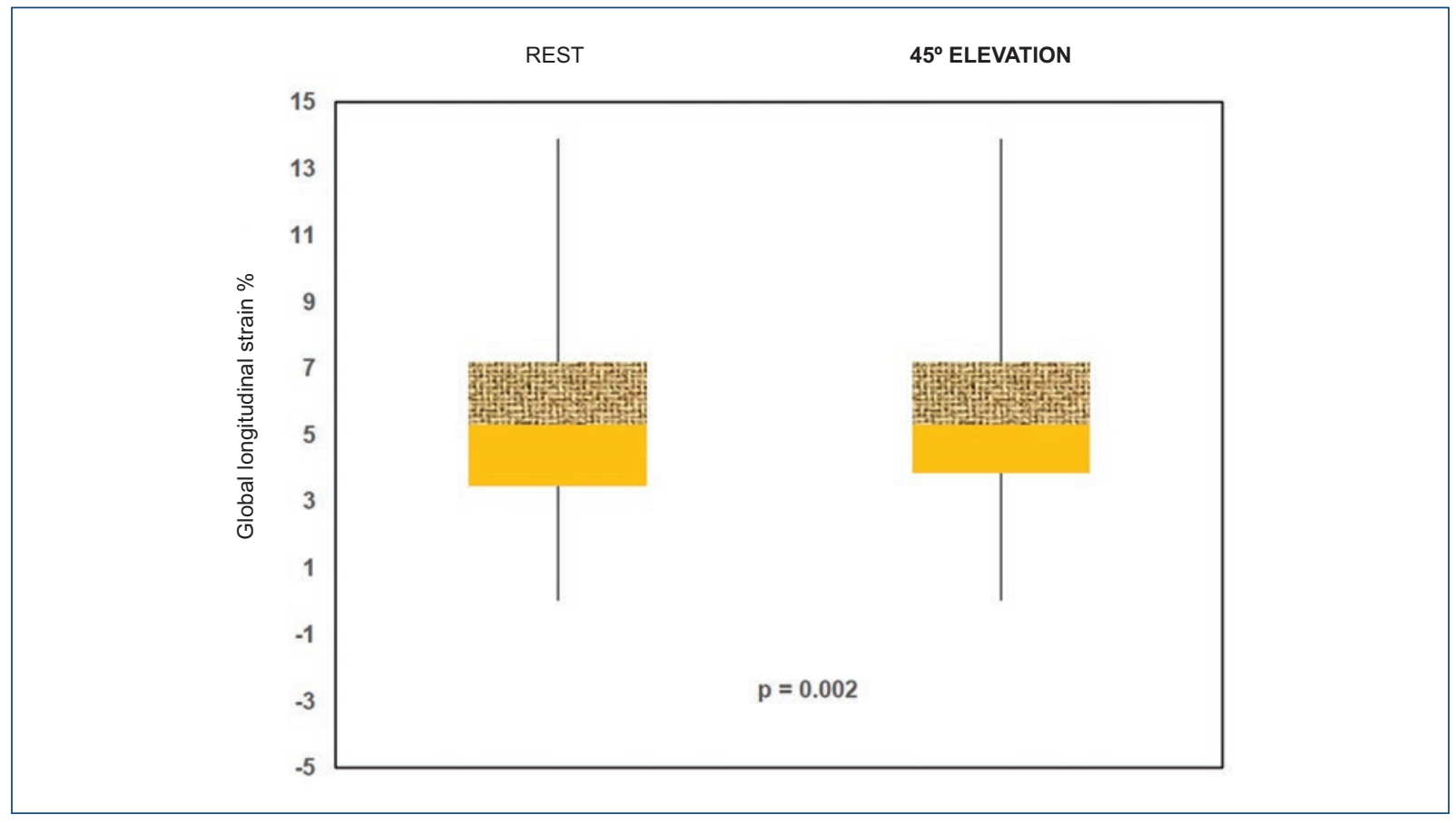

Figure 2. Box and whisker plot showing mean differences and bias. Right ventricle global longitudinal strain percentage distribution, at rest and with leg elevation to $45^{\circ}$.

segment. We found that the strain is more negative with leg elevation to $45^{\circ}$, which supports that the greater the stretching of the myocardial fiber by increasing the preload, the more negative the generated deformation, indicating that there is a greater shortening of the fiber, and this method can measure those differences.

\section{Conclusions}

Despite the limitations of the method for analyzing the $\mathrm{RV}$ in subjects without cardiopulmonary compromise, this method was sensitive to detect differences in GLS and SLS in basal and mid-RV free-wall segments. 


\section{Conflicts of interest}

The authors declare not having any conflicts of interest or having received any funding to carry out this study.

\section{Ethical disclosures}

Protection of people and animals The authors declare that no experiments have been conducted on humans or animals for this research.

Confidentiality of data The authors declare having followed the protocols of their work center on the publication of patient data.

Right to privacy and informed consent The authors declare that no patient data appear in this article.

\section{References}

1. Cui X, Washio T, Chono T, Baba H, Okada JI, Sugiura S, et al. Deformable regions of interest with multiple points for tissue tracking in echocardiography. Med Image Anal. 2017;35:554-69.

2. Claus P, Omar AMS, Pedrizzetti G, Sengupta PP, Nagel E. Tissue tracking technology for assessing cardiac mechanics principles, normal values, and clinical applications. JACC Cardiovasc Imaging. 2015; 8(12):1444-60.

3. Burri MV, Gupta D, Kerber RE, Weiss RM. Review of novel clinical applications of advanced, real-time, 3-dimensional echocardiography. Transl Res. 2012;159(3):149-64.

4. Mor-Avi V, Lang R, Badano L, Belohlavek M, Cardim NM, Derumeaux G, et al. Current and evolving echocardiographic techniques for quantitative evaluation of cardiac mechanics: ASE/EAE consensus statement on methodology and indications endorsed by Japanese Society of Echocardiography. Eur J Echocardiogr. 2011;12(3):167-205.
5. Sun JP, Lee AP, Wu C, Lam YY, Hung MJ, Chen L, et al. Quantification of left ventricular regional myocardial function using two-dimensional speckle tracking echocardiography in healthy volunteers - A multi-center study. Int J Cardiol. 2013;167(2):495-501.

6. Stöhr EJ, Shave RE, Baggish AL, Weiner RB. Left ventricular twist mechanics in the context of normal physiology and cardiovascular disease: a review of studies using speckle tracking echocardiography. Am J Physiol Heart Circ Physiol. 2016;311(3):H633-44.

7. Stefani L, Toncelli L, Gianassi M, Manetti P, Di Tante V, Vono MR, et al. Two-dimensional tracking and TDI are consistent methods for evaluating myocardial longitudinal peak strain in left and right ventricle basal segments in athletes. Cardiovasc Ultrasound. 2007;5:7.

8. Teske AJ, De Boeck BWL, Melman PG, Sieswerda GT, Doevendans PA, Cramer MJ. Echocardiographic quantification of myocardial function using tissue deformation imaging, a guide to image acquisition and analysis using tissue Doppler and speckle tracking. Cardiovascular Ultrasound, 2007;5:27.

9. McDaniel J, Fjeldstad AS, Ives S, Hayman M, Kithas P, Richardson RS. Central and peripheral contributors to skeletal muscle hyperemia: response to passive limb movement. J Appl Physiol (1985). 2010;108(1):76-84.

10. McDaniel J, Hayman MA, Ives S, Fjeldstad AS, Trinity JD, Wray DW, et al. Attenuated exercise induced hyperaemia with age: mechanistic insight from passive limb movement. J Physiol. 2010;588(Pt 22):4507-17.

11. Trinity JD, McDaniel J, Venturelli M, Fjeldstad AS, Ives SJ, Witman MA, et al. Impact of body position on central and peripheral hemodynamic contributions to movement induced hyperemia: implications for rehabilitative medicine. Am J Physiol Heart Circ Physiol. 2011;300(5):H1885-91.

12. Hayman MA, Nativi JN, Stehlik J, McDaniel J, Fjeldstad AS, Ives SJ, et al. 2010. Understanding exercise-induced hyperemia: central and peripheral hemodynamic responses to passive limb movement in heart transplant recipients. Am J Physiol Heart Circ Physiol. 2010;299(5): H1653-9.

13. Chadi BH. Cardiac arrest: Vascular resuscitation by leg elevation. Resuscitation. 2013;84(5):e59.

14. Sabatier C, Monge I, Maynar J, Ochagavia A. Assessment of cardiovascular preload and response to volume expansion. Med Intensiva. 2012; 36(1):45-55.

15. Dong SJ, Hees PS, Huang WM, Buffer SA Jr, Weiss JL, Shapiro EP. Independent effects of preload, afterload and contractility on left ventricular torsion. Am J Physiol. 1999;277(3):H1053-60.

16. Burns AT, La Gerche A, D’Hooge J, Maclsaac AI, Prior DL. Left ventricular strain and strain rate characterization of the effect of load in human subjects. Eur J Echocardiogr. 2010;11(3):283-9. 